\title{
Nurses' experiences of transition to community-based practice
}

\author{
Clare Harvey*1, Desley Hegney ${ }^{2}$, Lily Tsai ${ }^{3}$, Sandy Mclellan ${ }^{4}$, Diane Chamberlain ${ }^{5}$, Agnieszka Sobolewska², Elspeth \\ Wood $^{1}$, Joyce Hendricks ${ }^{6}$, Troy Wake ${ }^{7}$ \\ ${ }^{1}$ School of Nursing, Midwifery and Social Science, Townsville Campus, Central Queensland University, Australia \\ ${ }^{2}$ Research Division, Brisbane Campus, Central Queensland University, Australia \\ ${ }^{3}$ School of Nursing, Midwifery and Social Science, Brisbane Campus, Central Queensland University, Australia \\ ${ }^{4}$ School of Nursing, Midwifery and Social Science, Mackay City Campus, Central Queensland University, Australia \\ ${ }^{5}$ College of Nursing and Health Sciences, Flinders University of South Australia, Australia \\ ${ }^{6}$ School of Nursing, Midwifery and Social Science, Wide Bay Campus, Central Queensland University, Australia \\ ${ }^{7}$ Mackay Hospital and Health Service, Department of Health, Australia
}

Received: January 6, 2019

DOI: $10.5430 / \mathrm{cns} . \mathrm{v} 7 \mathrm{n} 3 \mathrm{p} 1$
Accepted: April 12, 2019

Online Published: April 23, 2019

\begin{abstract}
Objectives: This paper describes the findings from interviews, presented as the second stage of a study aimed at developing a career pathway for community nursing and midwifery for one Australian state, with a particular focus on early transition to community-based practice.

Background: With the increasing incidence of chronic conditions, health services are focused on primary and community care as the central point of care provision, and with it, the realisation that nurses have a central role to play in care delivery. Yet, community nursing is a poorly defined area of practice, and it is often seen as an unattractive career option.

Methods: Semi-structured interviews were conducted with seven experienced registered nurses currently employed and working in the community. Data analysis was undertaken using a pragmatic approach that allowed for the examination of themes emerging from the participant narratives. One member of the research team conducted interviews, with cross-checking of transcripts undertaken by other members of the team. Narrative was drawn from the transcripts and aligned to themes emerging from a draft pathway informed by a systematic review. COREQ checklist was adhered.

Results: Participants identified elements essential to a good transition that included responsive orientation, innovative leadership and the development of community-based networks related to social, legal, financial and practical elements of care. Experiential knowledge and a sense of belonging within the community were two important factors considered essential to successful transition. Conclusion: Community nursing is a specialised practice which requires a revision of expectations, preparation for practice and acknowledgement of its value, before nurses can become responsive to the changing community emphasis on health service delivery.

Potential implications: For a career pathway to accommodate early transition into community practice, key issues need to be addressed in relation to educational preparation, support for practice, and acceptance.
\end{abstract}

Key Words: Community nursing, Nurses, Nursing, Nursing workforce, Specialised nursing

*Correspondence: Clare Harvey; Email: c.1.harvey@ @qu.edu.au; Address: 1/538 Flinders Street, Townsville City, Queensland, 4810, Australia. 


\section{INTRODUCTION}

The current trends in Australian health care delivery have been characterized by escalating costs of care and service demands due to the rise of an ageing population and complex and chronic conditions. ${ }^{[1,2]}$ Globally, there is a growing realisation that care needs to shift to primary and community care services, alongside a focus on hospital avoidance. ${ }^{[3,4]}$ According to the World Health Organization, ${ }^{[4]}$ making this shift requires multiple and complementary reforms. Expanding the community nursing workforce is one strategy responding to the changing service delivery dynamic. ${ }^{[5,6]}$ Despite this acknowledgement, there is concern that the Australian nursing workforce may not meet future care capacity demands across all sectors of health care delivery. ${ }^{[7]} \mathrm{Com}-$ munity nursing and midwifery is one of the areas of concern, where future recruitment now requires rigorous professional preparation for an increasingly complex patient population, and innovative approaches make community practice an attractive career option.

This paper describes the second stage of a three-stage project to develop a pathway to support future requirements of the community nursing and midwifery workforce. The second stage analysed the experiences of seven community-based registered nurses working in regional Queensland, Australia, as they transitioned to the role of community nurse.

The objective of the overall project was to explore the educational, clinical, industrial and organisational issues related to nursing and midwifery career pathways into communitybased practice, and in particular as they relate to new graduate and early career nurses and midwives. The outcome of this investigation was to develop a comprehensive career pathway as part of Queensland Health's Graduate Enhancement projects aimed at increasing service capacity through the early transition of graduates into the nursing and midwifery workforce.

\section{Background}

Community nursing is an umbrella term that encompasses a variety of roles and practices located in community settings within metropolitan, regional, rural or remote areas. The World Health Organization's ${ }^{[8]}$ definition of community nursing is:

"a special field of nursing that combines the skills of nursing, public health and some phases of social assistance and functions as part of the total public health programme for the promotion of health, the improvement of the conditions in the social and physical environment, rehabilitation of illness and disability."
Seventy percent of the state of Queensland is recognized as a rural or remote region, judged as such by their population density and distance away from the nearest metropolitan city. Services can include larger regional hospitals, smaller rural hospitals, multi-purpose services/centres, or remote nursing posts, getting smaller, the more remotely located they are. The workforce in these services vary, with the larger services having on-site medical and allied health personnel and smaller services often staffed by nurses and Aboriginal Health Workers with remote or visiting access to medical and allied health support. This means that the more remote the service, the more diverse the skills that are required for the nursing workforce to manage care..$^{[9,10]}$

Barret, Terry ${ }^{[11]}$ noted that community nurses must be able to deal with anything from routine dressings to emergencies, and therefore require a broad set of skills, a good network of contacts and an understanding of diverse range of clinical presentations. A community nurse in a metropolitan service will be one of a team of health professionals working in close proximity to the area in which practice is located; metropolitan based nurses can also have a variety of roles and support networks which do not follow a consistent role description across services. While large regional health services are often configured similarly to metropolitan health services, they can form a "hub" for smaller rural hospitals/remote nursing posts. The more isolated the service is from a larger hub the more likely distinct roles for community nurses become integrated into the health service. For example, multipurpose health services can cater to a town's immediate needs through community and acute care in which nurses may not necessarily have a major community role, rather they may work in multiple roles within the service. Nurses working in more remote areas work in primary, emergency, aged care and community settings with primary care services located within a $200-400 \mathrm{~km}$ radius; and, remote area centres are often one-nurse clinics, serviced by the Royal Flying Doctor Service and/or other fly-in, fly-out services and through the use of Telehealth consultations. ${ }^{[12]}$ The more remote the service, the greater the requirement for dual registration (nurse/midwife) or at the very least, an obstetric competency alongside a nursing registration.

An early or new graduate transition to community practice has not been a preferred choice in community nursing recruitment. ${ }^{[13]}$ This may be attributable to the perception that community nurses are a "jack of all trades, master of none." ${ }^{[14]}$ Moreover, community nursing is invisible, with community nursing roles defined by service need rather than professional appointment. ${ }^{[1]}$ 


\section{Methodology}

\subsection{Project overview}

As indicated, the interviews formed the second of three stages of a project to develop a community nursing and midwifery pathway to expedite early transition into community practice settings. The first stage involved a systematic review to define a community nursing and midwifery scope of practice; to identify education and clinical preparation required for community practice; and to find out if there were any preferred models for community preparation for practice. Information from the systematic review revealed the importance that the personal self, professional self, and belonging, had on the transition process in community practice, and it was those insights that informed the development of a draft pathway, created to assist in the scaffolding of information for the interviews, as the second stage of data gathering (see Figure 1). The development of the draft pathway was also informed by recent work undertaken by Queensland Health to support rapid transition to specialty practice for new graduate nurses (SwIM) ${ }^{[15]}$ and the development of a Life Long Learning Framework. ${ }^{[16]}$ Benner's "novice to expert" philosophy underpinned the approach to pathway development. ${ }^{[17]}$ It should be noted that the systematic review examined nursing and midwifery, which is why the draft pathway has reference to both disciplines. Although the interviews sought nursing and midwifery participation, no midwives responded, thus, we refer to nurses only when describing the findings in this paper. Because the following diagram has been published in a systematic review, it remains as a reference to both nursing and midwifery. The final pathway (which is not in this paper's remit), removed the reference to midwives, and the final white paper presented to Queensland Health provided the pathway as recommended for nurses only.

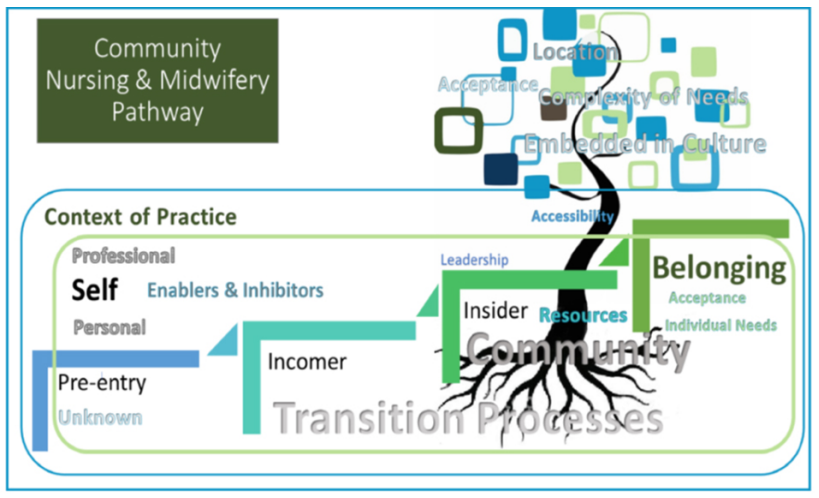

Figure 1. Flow chart of search results of studies from searching and screening

This second stage was designed as a primary research project and involved in-depth interviews with nurses working in community settings, to find out about their experiences of transition into community practice, and it is this stage that this paper focuses on. Information from these two stages then informed the final stage, which was a Delphi study with nursing experts in community-based practice, after which the final pathway was established.

\subsection{The interviews}

The aim of this stage was to explore the experiences of community nurses as related to their transition as registered nurses to their role of community-based practice.

\subsection{Research questions}

(1) What are the experiences of registered nurses as they transition to community-based speciality practice?

(2) What are the inhibitors and enablers that support the early transition of a registered nurse to a community practice role?

(3) Is there a difference in the needs of the early career nurse transitioning to community nursing compared with the traditional model of the experienced nurse?

(4) Do these findings support the draft community nursing transition model as the basis for a community nursing pathway?

\subsection{Methods}

Open-ended questions were used to encourage participants to describe their experiences about their transition to community practice in their own words and in their own way. A guide to the interviews was developed from which the interviewer could draw on, when progressing any discussion with participants, although nurses were allowed to describe their experiences in their own way (see Table 1). This allowed for a deeper meaning to be shared, and new insights into the phenomenon of transitioning to the role of a community nurse, examined.

A pragmatic approach to the analysis of the narratives was used because it is practical and flexible. ${ }^{[18]}$ It is concerned with nature of reality and the relationship between theory and its application, using methodologies that are appropriate for the proposed systematic inquiry. ${ }^{[19,20]}$ Language and action are symbiotic, where meanings are communicated through social interaction, understanding and negotiation. In socially orientated workplaces, action and text convey differences of opinions but also consensus in how people work together in a common environment, and how they make sense of organisational directives. ${ }^{[21]}$ Hagler and Brem ${ }^{[21]}$ contend that arguments are "shaped by knowledge, motives and goals, and social convention", the appraisal for which is evaluated against a chosen standard. By tapping into nurses' 
views about their experiences, the authors suggest that we can uncover multi-layered factors that manifest in how nurses describe their reality. In our case, nurses' experiences of transitioning into community practice is the standard by which we evaluated their views, to explore the applicability, or not, of the draft pathway emerging from the systematic review.

The interrogation of the narrative from interviews used the draft pathway model as the platform for analysis. This provided opportunity to explore the concepts described by the participants and then compared them with the outcomes of the systematic review, mapping these commentaries to the draft pathway. Thus, interview questions were designed not only to gather more data about the model, but also to ascertain the model "fit". Enablers and inhibitors around these concepts that had emerged in the systematic review, were also explored. The approach aimed at supporting the creation of new knowledge ${ }^{[22,23]}$ upon which to build the final stage of the project, that being the Delphi study with clinical experts in clinical practice.

Table 1. Guide to interviews

Community pathways guideline for interviewing RNs and RMs

1. How long have you been working in your community-based service?

2. What drew you to embarking on a career in community-based services?

3. Tell us about your induction and orientation to community-based work?

4. How long had you been registered when you entered community-based services?

a. (If numbers of years) - How do you think this experience helped to prepare you for your role in the community?

b. (If no experience) - What experience do you think might have assisted in your settling-in to community practice?

5. Tell us what was good about your experience.

6. Tell us what was not so good about your experience.

7. Tell us about how you felt when entering into community-based practice.

a. What helped your settling in period?

b. What did not help you in your settling in period?

8. Tell us about your upskilling and preparation for practice in the community-based setting. What opportunities were available to you? How were you supported?

9. Tell us about your ongoing learning and professional development in the community-based service.

10. What would you say to a new graduate who is keen on working in a community-based service?

11. If you were a new person going into community-based practice again, what skills and knowledge do you think would be helpful in the preparation of your role?

\subsection{Ethical considerations}

Approval for the study was granted by Queensland Health Ethics Committee.

\subsection{Data collection}

Purposive and snowball sampling was used to recruit participants. Inclusion criteria were registered nurses working in the community of one regional health service catchment area. A total of 35 registered nurses and midwives working in that community practice setting were invited to participate. The invitations were sent out by one research member working in the community who had access to contacts within the region. An information sheet outlining the project, along with consent forms were emailed to the potential participants, asking them to contact the lead researcher if they wished to participate in the study. Seven nurses agreed to participate and returned signed consents to the lead researcher. Participants were then contacted by one member of the research team and a mutually agreed time was made for a telephone interview. Telephone interviews were undertaken because of the extensive geographical distances between locations in the region. Interviews were semi-structured, recorded and later transcribed verbatim by a professional transcriber who signed a confidentiality agreement.

One member of the research team conducted all the interviews to provide consistency in discussion. All seven interviews were conducted over a three-week period during the month of June 2018. Despite the small numbers, data saturation was achieved. Interviews ranged from 12-26 min in duration with an average of 17 minutes. Transcripts and recordings were cross-checked by one researcher for accuracy and all the interviews were de-identified.

\subsection{Data analysis}

Two researchers independently reviewed the transcripts examining the textual response relating to each individual's experience. It was apparent that, with the exception of the participants providing a description of community-based practice (see Table 1 - "participant suggestions"), the con- 
cepts previously identified in the systematic review emerged. Care was taken not to "force" the findings into the draft model. This was particularly important as this stage was designed as primary research to gather data, not to test the model. Quotes from the narrative were divided into inhibitors and enablers for transitioning at each step along the pathway (see Appendix). This method was systematic and repetitive, with four researchers independently revisiting recordings and transcripts multiple times to ensure that the meaning and understanding gained was an accurate representation of the participant's interviews. The results and discussion follow the elements on the draft pathway and will be discussed under those headings.

\section{Results}

Participants had worked in community nursing from between 0-30 years, with one having just commenced in community nursing at the time of interviews. Five of the participants had extensive experience as a registered nurse prior to commencing their community nursing career, with only one nurse having transitioned immediately into community nursing. One nurse did not disclose how many years s/he had worked in nursing prior to transition. Five of the nurses were employed by a government service and two by a non-government organisation.

\subsection{Pre-entry}

Pre-entry refers to the student nurse experience prior to entering the speciality and can take the form of exposure to community nursing practice, and/or, most commonly for early career transitions, of a community clinical placement during their pre-registration program. At this stage, participants noted how the personal self influenced their experience:

"[Reflecting on own clinical placement as undergrad student] I really thoroughly enjoyed my work in the [specialty area] field when I was doing my grad nurse, which was a different role." (CP7)

as well as their professional self:

"I got awesome placements. I got to do a lot of district nursing ... That prepared me for community and I think the training overall prepared me." (CP1)

When asked about what they thought pre-registration students required for community practice, one participant suggested:

"I think all student nurses should have the opportunity that they should have to complete, I don't

Published by Sciedu Press know, eight to 12 weeks of community health nursing in their training to get that idea, but I think it would be good to have, like, a specialist training program just for community nursing, because it is so very different to hospital nursing." (CP6)

Participants also noted that formalised transition processes during clinical placement may also enhance transition. For example:

"I think there needs to be a [considering what a new graduate might need] - like, in your third year or in a post grad year you could opt to do that, an extra or a certificate in community, on top of in a, you know? Like your third year, maybe do - if you think you're going to go down that community path you do more of your placements in a community setting, because it is very different and you are on your own. You're completely on your own and it's purely that - I'm sure I - it's because I went from working in a specialised unit to dealing with that specialised condition in the community, that I wasn't as thrown by it I think." (CP5)

\subsection{Incomer}

The incomer stage in the model refers to the time when the transition nurse begins practice in the area of speciality.

At the Personal Self level, participants noted that on entry, there was little support for the new role, which did require new skills as well as those they already had developed in a different practice setting.

"Hit the ground running ... that was kind of scary... and you're suddenly out on the road going, there's no one to tell me about morning tea ... I was able to prioritise my clients, [but] I wasn't shown how to." (CP1)

With regard to the professional self, participants talked about how their previous knowledge supported their new transition:

"I'll tell you why I coped with that. It's because it was a specialist area of community nursing. So it was a respiratory - it was a home based nursing intervention for respiratory patients. So I'd come from a respiratory unit in the hospital. And then I just transferred that knowledge into the community setting." (CP5)

While others noted how a lack of experience affected the ability of the incomer to cope with their role. 
"I've got a young lass at the moment [new graduate], she's not been with us very long, and she trained, went into a residential unfortunately after her training, and I didn't realise she had trouble prioritising her clients. She didn't know how to. She didn't know what to look for, to see who you should do first. Whereas I just assumed as a nurse, she'd know." (CP1)

Transition Processes also had what could be seen as inhibitors and enablers during this time. Enablers included both informal process, such as being introduced to the broader team, shadowing, informal feedback:

"Being introduced to the other health staff around the area, you know, like the hospital staff, the doctor. Being, also, knowing what was the really important part is, who can I refer to, where can I go to, to get help if this is beyond me?" (CP4)

"And then the following week I got to shadow colleagues within my team, go out with them, which was really good." (CP6)

"If you're unsure, there was always, like the Director of Nursing was here for feedback, or you came back at morning tea, the other RNs were here, or lunch. That was good." (CP1)

Formal transition process such as formal orientation and buddying were also seen as enablers by some participants (see Table 1).

"I was buddied, which was great, but you came back to the centre. So the team was very good." (CP1)

"There was a weekly orientation timetable that was there with Monday to Friday, all the times, this is where I was going, who I was going to be with, which was just great; it was just good that it was all organised and that was there." (CP6)

However, there were also inhibitors to successful transition seen to be influencing the transition processes on immediate entry to practice. For example, many facilities in Queensland have the majority of their mandatory training programs online. One participant noted that this orientation program was only offered on-line which she believed was inappropriate.

"Welcome to [name of service], here's a computer screen, please sit there for the next two days and just go through all these training modules." (CP1)
There was also concern over the lack of a "buddy", "mentor" or "orientation" at this stage as well as problems with accessing any professional development to assist with learning new skills.

"There are some centres I know that don't buddy them." (CP1)

"Professional development, there is nothing... There is nothing that supports learning." (PC2)

"We didn't have a very good orientation, wasn't good at all and there was another nurse working there as well but then she became sick so then I was kind of it and then I was kind of just thrown in, so I found that really difficult, not having that orientation." (CP6)

While some participants noted the support they had from the Director of Nursing, another participant believed that she had no support from management, and like other participants noted that often "training" was done in their own time (see Table 1).

"I wasn't supported by my management to get to those training days either. So, a lot of time it was done in my own time." (CP7)

A common theme in the incomer period with regard to transition processes, both formal and informal, was that in most cases there were none. Rather the nurse "was kind of just thrown in" (CP6).

At the incomer stage, the participant was developing a "sense of belonging". Again, participants talked about the enablers to develop this belonging, as well as some inhibitors. However, this was not clearly defined. Participants considered their reasons for choosing a career in the community rather than identifying being settled in their new environment:

"I just liked the idea of just going into people's homes ... relaxed atmosphere ... I felt that I could probably do a bit more in the community in their homes than I could in the hospital." (CP6)

\subsection{Insider}

Insiders are described as those nurses who have been through the induction and orientation process and are now settling down to life and work in community practice. Nurses talked about how previous experience helped with this settling in process and discussed how this background was important in understanding the wider network required for caring for 
patients in a community setting. The personal and professional self, became one, where maturity, understanding and skill were all essential ingredients for the transition process. Examples of this narrative are:

"You have to be really honest with yourself. Have a good understanding of where your strengths are, where are areas that you might need to work on, what skills do you need... be flexible." (CP2)

The broader networking requirements were seen as essential to practice, knowing who one could call when there were socially related issues such as housing, social or financial problems that went beyond clinical practice.

"So you have to, I think, have a professional maturity about you and just an overall maturity in the work space, from whatever line that you come from, to just jump into community because you're working with everybody, from housing, and it always becomes the social issues." (CP2)

Others noted the change in support in the community environment and the need to "hit the ground running", was an inhibitor that had to be overcome.

"well you come out of your hospital like you're so used to a routine, and I can remember out in the community going because I was so used to being allocated. You know your morning tea, you went to first or second, lunch first or second, and you're suddenly out on the road going, there's no one to tell me about morning tea." (CP1)

The transition processes in this stage available were both formal and informal. Similar to the comments at the incomer phase, some participants noted there was no support and that they had to "learn on the job through trial and error" (CP4). Informal processes to add learning included supportive more senior staff:

"We had two senior nurses who were just really good, happy to share their knowledge, approachable." (CP6)

Whereas a new formal learning tool was seen as the weekly case conferences held:

"We had weekly care review case conference with our team..." (CP6)

Published by Sciedu Press
The sense of belonging at this stage was still focused on working out what was needed and how one was going to manage in the community, for example:

"Yes, it's trying to see what's working and what's not, trying not to duplicate what's already there and wasting resources, so it's a whole new learning experience... it's having the right supports in place I guess at this point, which at the moment there isn't a lot, from my perspective anyway." (CP2)

\subsection{Belonging}

The participants provided considerable new knowledge with regard to the factors that contributed to their feelings of belonging and wanting to continue to work in this field once they had passed the insider phase. Belonging, from a personal and professional self perspective, referred to becoming one with the health care team and the community in which one worked. It also included being able to manage practice confidently, and to identify what ongoing learning was required. Participants described this as an essential element of practice. Participants described a patient-centred approach to their work as part of belonging.

"It's about getting people to start questioning and looking at, well, okay, hang on, I need to do something about this, and taking ownership I suppose. Getting our clients to own their health, own what's happening to them." (CP4)

"It's a very rewarding area to work in... I found it exciting." (CP5)

Looking more broadly the service and the demographic was also important to provide a meaningful service:

"It's important that you look at being able to identify what are the trends, what are the areas that are of health, that are maybe growth areas in this area? So I started seeing a lot of people coming in with dementia, particularly undiagnosed dementia. And - so I took it upon myself, okay, I want to learn more about that so that's what I used my professional development towards." (CP4)

Problems with system were also identified:

"[Regarding ongoing funding] - The lack of understanding of what's needed, none of its really supported. Until you can put a case forward and then it always comes down to funding." (CP2) 
"Not having direct nursing leadership, because it comes under the [scale], on a different funding model and health model. So [I am] making it up as I go along." (CP2)

With regard to transition processes, there was no specific recommendation that had not been raised earlier. Again, participants also spoke about the additional and broader skills that they felt was needed in community practice. These included management, leadership, broader assessment skills, communication, law and justice:

"You need a degree of management I guess, yes, just to be able to prioritise, budget, all those sorts of things. Law and justice is always a good one as well as, as well as the legal guardianship type of stuff, to know your boundaries and that sort of stuff, and again, recognising those vulnerable communities." (CP2)

Participants also noted how economic influences such as funding can not only influence patient care, but also their ability to provide an effective service:

The lack of understanding of what's needed, none of its really supported. Until you can put a case forward and then it always comes down to funding. (CP2)

Importantly, one participant noted that health service policies need to change to focus more on prevention than a "sickness model".

"So we're still, for me, still putting the cart before the horse, and it still needs a lot more resources and light shone on it, to get real outcomes for people, rather than once they're in this acute system as you know, it's always in the sickness mode, not in the preventative model." (CP2)

\section{Discussion}

The data also provided validation for the previously developed model. Analysis of the free text responses to the questions, clearly identified similar themes and sub-themes to the findings from our previous systematic review. ${ }^{[24]}$ The need to have an experiential knowledge base upon which to make decisions within a dynamic clinical environment was evident, and it is this aspect that participants were concerned about most when discussing the pre-entry and incomer (as a new graduate) stage of transition. Participants believed that a lot more educational and organisational support was needed at the pre-entry stage into community practice to prepare them for their new role. Without this, many were expected to "hit the ground running".

Participants raised this issue also affected the newly graduated incomer. Participants described new graduates' application to practice as too naïve for what is often solo work, requiring a depth of knowledge and experience to draw on. In order to find out what participants thought about new graduates' entering community practice, nurses were asked to consider what might be important for such incomers. Suggestions included having more undergraduate clinical placements in the community, so that exposure to what is expected could be provided. Patten, O'Meara ${ }^{[25]}$ also found that interpersonal skills and an understanding of the socio-cultural norms were important.

As an experienced registered nurse incomer to speciality practice, participants described the shock at the change in environment even although they had previous clinical experience. Some of the participants indicated that they would not have coped with a transition to community practice without previous experience. Orientation was described as an essential element which needed to be structured and responsive to the person's knowledge base and confidence levels. Participants also acknowledged their own experiential knowledge as supporting transition to practice. Murphy and Janisse ${ }^{[26]}$ also found that applying an experiential learning method with competency-based orientation allowed for a more individual approach to transition. Participants indicated that orientation needed to embrace more than the operational requirements of the job, noting that networking and mentorship were important elements for nurses' transition from incomer to insider. It seemed that without this support, the early stages of being an incomer were taken up with finding out what one needed to know of the broader networks and community nuances. Illingworth, Aranda ${ }^{[27]}$ found that preparation for advanced practice roles in the community was dynamic and also complex, where students described their transition as “' reinventing' and 'recreating' themselves", which included dealing with cynicism from other team members, as well as learning about the broader clinical requirements practice. Moreover, Pijl-Zieber, Barton ${ }^{[28]}$ found that although theoretical approaches for student preparation for community practice was sound, the views of the services differed in what they believed students should know. Our participants also noted that preparation for practice depended upon the service's views and perceptions.

Ongoing learning opportunities depended on the leadership of the service. Most of the nurses spoke of finding their own learning opportunities and sometimes having to pay 
for this themselves. Mentorship was seen as the value of having someone more senior or experienced to provide that ongoing support in practice. Mills, Francis ${ }^{[29]}$ describe rural nurses' experiences of mentoring as "cultivating and growing" nurses and is driven by "cultural, political and clinical demands of the social world within which they exist". The authors found that it was about "getting to know a stranger" that required an open disclosure of self, because these people were working and living in a small community where personal and professional lives intermingled. When asked about what additional professional development community nurses would benefit from, participants from our study described the importance of networks within the community, and who to seek advice from, or refer to. This included the broader scope of practice that participants felt should be part of the community nurses' preparation for practice and these included, legal (e.g., what to do in a situation of domestic violence), practical (e.g., housing), safety (e.g., dealing with danger and risk), and financial knowledge (e.g., being able to manage a practice budget).

Belonging has been described as the inclusiveness of all participants where a culture of connection is built through relationships to promote a sense of belonging. ${ }^{[30]}$ The narrative of the participants demonstrated attempting to belong to their workplace, with the multidisciplinary team and with their community. The narrative became stronger as they transitioned, but they clearly struggled to define their role. This is understandable given the lack of any clearly defined role in policy documents. ${ }^{[31]}$ Nor is there any overarching policy or standardised education designed to prepare community nursing practice. Participants described their education preparation as ad hoc and self-directed. Additionally, they indicated that organisations did not really understand their role, with economics driving role establishment and sustainability. It was clear from their comments that a standardised pathway was needed to support nurses in developing and establishing the role. In a preliminary internet search for community nursing and midwifery pathways, remote area nursing was the only formal education pathway identified in the Australian context. ${ }^{[32]}$

The participants also struggled to visualise a "new" role which an newly graduated nurse would be able to transition successfully to community practice as their vision clearly was a registered nurse with general nursing skills and only being employed once experienced. ${ }^{[33]}$ However, the participants who had experience prior to transitioning, noted that the skills they needed in the hospital were fundamentally different. ${ }^{[34]}$

In addition to providing validation for our previous study, the interviews also provided new insights into the experiences of Published by Sciedu Press nurses in transitioning to community practice, particularly in the area of the development of belonging. Participants were clear that community nursing was far more than a general clinical practice. Rather, a successful transition required the nurse to develop a sense of belonging as belonging not only is necessary for well-being but also levels of belonging can influence the motivation and capacity to learn new skills. ${ }^{[35]}$

\subsection{Limitation}

Participants in the study represented a small convenience sample of registered nurses who were transitioned and currently working in the community of one regional health service catchment area. All interviews were conducted by telephone due to the geographic dispersion of participants. Whilst rich data were gathered, interviews conducted over the telephone may have impacted on the quality of data gathered. Due to the qualitative nature of the study, the results of this study cannot be generalised to represent broader community nursing population, although the findings do support the systematic review undertaken for this study (reference added following acceptance) and the development of our transition model. Unfortunately, we were unable to recruit any midwife participants to our study, and therefore their input is required at the next stage of this project to ensure the model is applicable not only to nurses but also to midwives.

\subsection{Implications and recommendations}

The interviews supported the information that emerged in the systematic review (reference added following acceptance). For a career pathway to accommodate early transition into community practice, key issues need to be addressed in relation to the personal and professional self, formal and informal transition processes and most importantly, a sense of belonging. All of these considerations need to occur in light of the context of practice. Recommendations drawn from the interviews are summarised in Table 2, and these recommendations were taken forward as part of the information preparation for the Delphi study.

\section{Conclusion}

This paper presents nurses' experiences and views of early transition to community-based practice. Key findings were required skills for successful transition to community nursing go beyond clinical nursing and assessment skills, and this should include ways to develop the personal and professional self. Further focus needs to be given on the availability of transition processes to ensure the special learning needs of working in a community such as networking across social, practical and legal boundaries are included. Belonging, both of the professional and personal self, is important for wellbeing and retention but also to ensure the provision of quality care. 
Table 2. Recommendations

\begin{tabular}{|c|c|}
\hline Pathway & Recommendations \\
\hline $\begin{array}{l}\text { The pathway } \\
\text { as a whole }\end{array}$ & $\begin{array}{l}\text { - A stepwise approach to clinical practice within a community focused environment, not merely a scaffold on } \\
\text { what services need or what skills nurses bring to the job. } \\
\text { - Structured, responsive education, inclusive of social, community and clinical requirements for } \\
\text { community-based practice. } \\
\text { - Adequate funding for community services to include ongoing learning, professional development and career } \\
\text { progression. } \\
\text { - Better marketing of the value of community nursing and the acknowledgment of a specialised clinical and } \\
\text { professional skill set. }\end{array}$ \\
\hline Pre-entry & $\begin{array}{l}\text { - Clinical placements of 8-12 weeks in a community setting. } \\
\text { - Focused community education in the undergraduate program. }\end{array}$ \\
\hline Incomer & $\begin{array}{l}\text { - Responsive, well planned induction and orientation that addresses clinical and community-based information } \\
\text { whilst also being responsive to previous nursing experience and clinical skills in relation to the time required for } \\
\text { orientation and support. } \\
\text { - Better support processes, particularly around networking and understanding the broader community systems } \\
\text { that support social and practical aspects of community work e.g. housing, legal, financial elements of care and } \\
\text { practice. } \\
\text { - Better policies related to occupational health and safety. } \\
\text { - Developing a buddy or mentor system for ongoing professional and clinical support. } \\
\text { - Structured ongoing learning and professional development opportunities focusing on community practice. This } \\
\text { includes in-service, non-certificate learning and community-focused postgraduate learning opportunities. }\end{array}$ \\
\hline Insider & $\begin{array}{l}\text { - } \text { Responsive and innovative service leadership. } \\
\text { - Employment security. } \\
\text { - Opportunities to support community integration and engagement. } \\
\text { - A defined career path that identifies career progression and lifelong learning. }\end{array}$ \\
\hline
\end{tabular}

\section{CONFLicts OF INTEREST Disclosure}

The authors declare they have no conflicts of interest.

\section{REFERENCES}

[1] Australian College of Nursing (ACN). Nurses are essential in health and aged care reform. Canberra: ACN; 2016.

[2] Australian Institute of Health and Welfare (AIHW). Australian Burden of Disease Study: Impact and causes of illness and death in Australia 2011. Canberra: AIHW; 2016.

[3] Alwan A. Global status report on non-communicable diseases 2010. Geneva: World Health Organisation; 2011.

[4] World Health Organisation. Primary health care, now more than ever. Geneva: World Helath Organisation; 2008.

[5] Askerud A, Conder J. Patient's experiences of nurse case management in primary care: a meta-synthesis. Australian Journal of Primary Health. 2017; 23(5): 420-8. PMid:28923163. https: //doi.org/10.1071/PY17040

[6] Commonwealth of Australia. National primary health care strategic framework. Canberra: Commonwealth of Australia; 2013.

[7] Henderson J, Koehne K, Verrall C, et al. How is primary health care concepturalised in nursing in Australia? A review of the literature. Health \& Social Care in the Community. 2014; 22(4): 337-51. PMid:23952616. https://doi.org/10.1111/hsc.12064
[8] World Health Organization. Framing the health workforce agenda for the sustainable development goals: biennium report 2016-2017 WHO Health Workforce. Geneva: World Health Organisation; 2017.

[9] Hegney D, McCarthy A, Pearson A. Effects of size of health service on scope of rural nursing practice. Collegian. 1999; 6(4): 21-6, 42. https://doi.org/10.1016/S1322-7696(08)60605-8

[10] Knight K, Kenny A, Endacott R. From expert generalists to ambiguity masters: using ambiguity tolerance theory to redefine the practice of rural nurses. Journal of Clinical Nursing. 2016; 25(11-12): 1757-65. https://doi.org/10.1111/jocn.13196

[11] Barret A, Terry DR, Lê Q, et al. Factors influencing community nursing roles and health service provision in rural areas: a review of literature. Contemporary Nurse. 2016; 52(1): 119-35. PMid:27264878. https://doi.org/10.1080/10376178.2016.1198234

[12] State of Queensland (Queensland Health). Better Health for the Bush. In: health Q, editor. Brisbane: State of Queensland (Queensland Health); 2014

[13] Aranda K. Community nurses' talk of equality and the discursive constitution of selves. Journal of Advanced Nursing. 2005; 51(2): 131-9. PMid:15963184. https://doi.org/10.1111/j.1365-2 $648.2005 .03476 . x$ 
[14] Gray C, Hogg R, Kennedy C. Professional boundary work in the face of change to generalist working in community nursing in Scotland. Journal of Advanced Nursing. 2011; 67(8): 1695-704. PMid:21375571.https://doi.org/10.1111/j.1365-2648. 20 10.05601. $\mathrm{x}$

[15] Hegney D, Chamberlain D, Harvey C, et al. The development of the TRANSPEC model: A systematic review of the factors influencing the effective rapid and early career TRANsition to a nursing SPECiality in differing contexts of practice. Under Review.

[16] Fox R, Booker C, Turbutt A. Framework for lifelong learning for nurses and midwives. Brisbane: Queensland Health; 2018.

[17] Benner P. From novice to expert: excellence and power in clinical nursing practice (Commemorative ed.). New Jersey: Prentice-Hall; 2001.

[18] Duffy G. Pragmatic analysis. In: Klotz A, Prakash D, editors. Qualitative methods in international relations. London: Palgrave Macmillan; 2008. https://doi.org/10.1057/9780230584129_11

[19] Rorty R. Truth and Progress. Cambridge: Cambridge University Press; 1998. https://doi.org/10.1017/CB09780511625404

[20] Snowden A, Atkinson J. Concurrent analysis: a pragmatic justification. Nursing Philosophy. 2012; 13(2): 126-41. PMid:22405019. https://doi.org/10.1111/j.1466-769X.2011.00523.x

[21] Hagler DA, Brem SK. Reaching agreement: the structure and pragmatics of critical care nurses' informal argument. Countemporary Educational Psychology. 2008; 33(3): 403-24. https://doi.org/ 10.1016/j.cedpsych.2008.05.002

[22] Creswell JW. Research design: Qualitative, quantitative, and mixed methods approaches. 4th ed. United States: Sage Publications; 2013.

[23] Goodsell TL, Colling M, Brown RB, et al. On past and future of community: a pragmatic analysis. The American Sociologist. 2011; 42(4): 277-87. https : //doi .org/10.1007/s12108-011-9137-y

[24] Harvey C, Hegney D, Sobolewska A, et al. Developing a communitybased nursing and midwifery career pathway - A narrative systematic review. PLOS One Open Access. 2019; 14(3): e0211160. https://doi.org/10.1371/journal pone.0211160

[25] Patten E, O'Meara P, Dickson-Swift V. Scoping review of the exclusion and inclusion of rural newcomers in community participation. Australian Journal of Rural Health. 2015; 23(3): 127-35. PMid:25945785. https://doi.org/10.1111/ajr.12188
[26] Murphy LJ, Janisse L. Optimizing transition to practice through orientation: a quality improvement initiative. Clinical Simulation in Nursing. 2017; 13(11): 583-90. https://doi.org/10.1016/j . ecns. 2017.07.007

[27] Illingworth A, Aranda K, De Goeas SM, et al. Changing the way that I am: students experience of educational preparation for advanced nursing roles in the community. Nurse Education in Practice. 2013; 13(5): 338-43. PMid:23046714. https://doi.org/10.1016/j. nepr.2012.09.009

[28] Pijl-Zieber EM, Barton S, Awosoga O, et al. Disconnects in pedagogy and practice in community health nursing clinical experiences: qualitative findings of a mixed method study. Nurse Education Today. 2015; 35(10): e43-e8. https ://doi.org/10.1016/j.nedt. 201 5.08 .012

[29] Mills J, Francis K, Bonner A. Getting to know a stranger - rural nurses' experiences of mentoring: a grounded theory. International Journal of Nursing Studies. 2008; 45(4): 599-607. PMid:17280671. https://doi.org/10.1016/j.ijnurstu.2006.12.003

[30] Good C, Rattan A, Dweck C. Why do women opt out? Sense of belonging and women's representation in mathematics. Journal of Personality and Social Psychology. 2012; 102(4): 700-7017. PMid:22288527. https : //doi.org/10.1037/a0026659

[31] Health Workforce Australia. Australia's Future Health WorkforceNurses Detailed. Canberra: Department of Health; 2014.

[32] CRANAplus. Pathway to remote professional practice. Adelaide: CRANAplus; 2015.

[33] Kennedy C, Christie J, Harbison J, et al. Establishing the contribution of nursing in the community to the health of the people of Scotland: integrative literature review. Journal of Advanced Nursing. 2008; 64(5): 416-39. PMid:19146511. https://doi.org/10.1111/j. 1365-2648.2008.04621.x

[34] Hunter B. Conflicting ideologies as a source of emotion work in midwifery. Midwifery. 2004; 20(3): 261-72. PMid:15337282. https ://doi.org/10.1016/j.midw.2003.12.004

[35] Levett-Jones T, Lathlean J. Belongingness: A prerequisite for nursing students' clinical learning. Nurse Education in Practice. 2008; 8(2): 103-11. PMid:18291327. https ://doi.org/10.1016/j.nepr.2 007.04 .003 